\title{
EDITORIAL
}

\section{Fixed minimum volume resuscitation: Pro}

\author{
Flavia R. Machado ${ }^{1,2^{*}} \mathbb{0}$, Mitchell M. Levy ${ }^{3}$ and Andrew Rhodes ${ }^{4}$
}

(c) 2016 Springer-Verlag Berlin Heidelberg and ESICM

\section{Dear Editor,}

The hemodynamic hallmarks of sepsis are arterial vasodilatation and increased capillary permeability. The fluid shift from the intravascular space together with the decrease in systemic vascular resistance and altered ventricular performance may lead to a relative hypovolemia and hypotension contributing to tissue hypoperfusion. As a consequence, fluid resuscitation is a key step to treat sepsis when signs of hypoperfusion are present. It is widely acknowledged that a lack of adequate fluid resuscitation during the first initial and crucial hours of hypoperfusion can have hazardous consequences in terms of organ dysfunction. Insufficient fluid resuscitation leads to delayed or absent shock reversal, and over-reliance on vasopressors, which is equally or even more harmful. For instance, the use of vasopressors in the presence of hypovolemia can lead to acute kidney injury (AKI) [1]. Sepsis is a leading cause of AKI among critically ill patients and both are associated with high mortality rates. Although the physiopathology of AKI is multifactorial [2], the restoration of normovolemia is a necessary step to prevent or reverse the pre-renal component of AKI.

The Surviving Sepsis Campaign (SSC) guidelines indicate fluid resuscitation with $30 \mathrm{~mL} / \mathrm{kg}$ within $3 \mathrm{~h}$ for all patients with hypotension or hyperlactatemia. The recommended approach is the use of a fixed initial volume followed by titration according to response, either based on dynamic (e.g., change in pulse pressure, stroke volume variation) or static (e.g., arterial pressure, heart rate) variables and careful administration of more fluids as needed. This initial fluid volume, around $2.0 \mathrm{~L}$, should

\footnotetext{
*Correspondence: frmachado@unifesp.br

${ }^{1}$ Anesthesiology, Pain and Intensive Care Department, Federal University of Sao Paulo, Sao Paulo, Brazil

Full author information is available at the end of the article
}

For a contrasting viewpoint, please go to doi:10.1007/s00134-016-4581-3. be sufficient to correct hypovolemia and is very unlikely to cause significant harm in virtually any patient. This approach aims to ensure an early and minimal correction of hypovolemia. The administration of $30 \mathrm{~mL} / \mathrm{kg}$ is not meant to be the total amount of resuscitation. Some patients may need considerably more fluid than this, and this must be assessed on an individual patient basis by clinicians at the bedside titrating additional fluid against clinical endpoints.

There is no randomized control trial (RCT) comparing these two different strategies, i.e., a fixed initial volume followed by titration or a more restrictive strategy in which titration is used from the start of resuscitation. RCTs assessing restrictive fluid strategies in the early phases of shock are also lacking. The results of the single RCT performed to date, the FEAST trial, are not generalizable and certainly not adaptable to the adult population [3]. FEAST was conducted in African children, with a mean age of 24 months, most of whom (57\%) had malaria and $32 \%$ had hemoglobin levels lower than $5 \mathrm{mg} / \mathrm{dL}$. There was no (or minimal) access to positive pressure ventilation. Fluid resuscitation might result in different outcomes in the presence of malaria and severe anemia. Severe dilutional anemia is potentially detrimental and could have contributed to the increased mortality in the fluids arms as patients randomized to the control group received blood transfusions while in these groups patients were receiving fluid bolus. It is also notable that there were no reports on the length of time needed to reach the study hospitals but a delay is certainly expected in Africa. It is well known that delays in resuscitation are associated with worse outcomes. Another RCT, the FACTT trial, compared liberal and restrictive strategies in fluid resuscitation in patients with acute respiratory distress syndrome (ARDS) [4]. The focus was not the first hours of resuscitation and patients with shock were taken out of the protocol for the restrictive fluid arm until

\section{Springer}


Table 1 Amount of fluids received by patients in the control arm in the EGDT trials

\begin{tabular}{|c|c|c|c|c|}
\hline Period & Rivers & PROCESS & ARISE & PROMISSE \\
\hline Prior to randomization $(\mathrm{mL})$ & NA & $2083 \pm 1405$ & $2591 \pm 1331$ & $1790(1000,2500)^{\mathrm{a}}$ \\
\hline Prior to randomization $(\mathrm{mL} / \mathrm{kg})$ & NA & $28 \pm 21$ & $34.7 \pm 20.1$ & NA \\
\hline Between 0 and $6 \mathrm{~h}$ after randomization $(\mathrm{mL})$ & $3499 \pm 2438$ & $2279 \pm 1881$ & $1713 \pm 1401$ & $2022 \pm 1271$ \\
\hline Between 0 and $6 \mathrm{~h}$ after randomization $(\mathrm{mL} / \mathrm{kg})$ & NA & NA & $23.2 \pm 21.2$ & NA \\
\hline
\end{tabular}

Results are expressed in mean \pm standard deviation or median (25-75\%).

NA not available

a Plus $500(255,500)$ pre-hospital

shock resolved. This prospective change in the treatment strategy precludes any generalizability of the restrictive strategy in FACTT to resuscitation in sepsis.

Several observational studies support the concept of early fixed minimal volume in patients with sepsis and hypoperfusion. Previous reports for the SSC database clearly show that the administration of a minimum of $20 \mathrm{~mL} / \mathrm{kg}$ of fluids along with the use of vasopressors to keep mean arterial pressure greater than $65 \mathrm{mmHg}$ was associated with a reduction in the risk of death [5, 6]. Similar findings were reported by the multinational IMPRESS study, comprising 1794 patients from 618 ICU in 62 countries [7]. In a propensity-weighted analysis of 2020 patients, the compliance with fluid resuscitation was independently associated with a reduction in the risk of death (OR 0.448, $95 \%$ CI 0.306-0.632, $p=0.001$ ) [8]. In 14,115 patients included in a prospective before-after study, a multivariate analysis showed that administration of 1-2 L crystalloids within the first $6 \mathrm{~h}$ was associated with a lower mortality rates [9]. There is also additional, although indirect, evidence of benefit in using a fixed amount of fluids in the first hours of resuscitation coming from the EGDT trials [10-13]. All these trials demonstrated low mortality rates in their control arm. In both ARISE [12] and PROMISE [13], patients were considered eligible if they had hyperlactatemia or if hypotension persisted after a fluid bolus of $1000 \mathrm{~mL}$. However, the total amount of fluids actually received prior to randomization was $34.7 \mathrm{~mL} / \mathrm{kg}$ in ARISE and around $2000 \mathrm{~mL}$ in PROMISSE (no body-weighed data available). Similarly, PROCESS included patients with hyperlactatemia or hypotension refractory to $20 \mathrm{~mL} / \mathrm{kg}$ of fluids [11]. Although they modified this requirement lately in the trial to $1000 \mathrm{~mL}$, the mean amounts of fluid received prior to randomization were $30.5,29.2$, and $28.0 \mathrm{~mL} / \mathrm{kg}$ in the three study arms (around 2000-2200 mL) (Table 1). These findings suggest that giving at least $30 \mathrm{~mL} / \mathrm{kg}$ as the first-line therapy for hyperlactatemia or hypotension is now an international standard of care. Interestingly, even after randomization the patients continued to receive fluids in similar amounts as the pre-randomization phase in the control arms, suggesting that this amount of fixed volume was not considered sufficient (Table 1). It is reasonable to conclude that the approach taken in these three larger international RCTs is consistent with the approach we recommend here.

Additionally, none of these studies showed that the fixed amount of fluids strategy is associated with harm. Although several researchers have suggested an increase in morbidity and mortality associated with positive fluid balances [14], the vast majority of these papers have analyzed fluid balance during the whole ICU stay or during the first ICU days and not in the first hours of shock. Some clinicians are reticent to give $30 \mathrm{~mL} / \mathrm{kg}$ in patients with heart failure or chronic kidney failure because of the theoretical risk of volume overload. However, a recent before-after study in patients with intermediate levels of lactate $(2-4 \mathrm{mmol} / \mathrm{dL})$ showed that fluid resuscitation with $30 \mathrm{~mL} / \mathrm{kg}$ was associated with a reduction in the risk of death, primarily in patients with heart failure or chronic kidney disease [15]. The impact in mortality remained significant over 1 year after the inclusion with no increase in adverse events. This finding reinforces the importance of early fluid resuscitation in all patients with sepsis and any degree of lactic acidosis, even in patients with renal or cardiac failure. There is also no evidence that aggressive fluid resuscitation in the first $6 \mathrm{~h}$ worsens respiratory dysfunction and leads to mechanical ventilation $(\mathrm{MV})$. Although patients in the EGDT arm receive more fluids in the first $6 \mathrm{~h}$, only $2.6 \%$ of those not under MV needed to be ventilated within the $7-72 \mathrm{~h}$ as compared to $16.8 \%$ in the control arm [10]. The EGDT arm and the protocol-based arm, in ARISE and PROCESS, received more fluids but there was no difference in the percentage of patients needing $\mathrm{MV}$ as compared to the other arms $[11,12]$.

Unfortunately, the clinical reality is that physicians are far more prone to under-resuscitate than otherwise. The change in behavior during the past few years is striking. Patients in the control arm of the Rivers trial received more than $13,000 \mathrm{~mL}$ in the first $72 \mathrm{~h}$ while those in the usual care arm of the new EDGT trials received around 
$6000 \mathrm{~mL}$ [10-13]. In this context, a necessary step to ensure minimal treatment is to set goals of care, a wellestablished strategy in quality improvement initiatives. This is even more relevant in resource-limited settings where access to knowledge is limited and key treatment steps need to be given in simple messages. The ability to assess fluid responsiveness is not a reality in the vast majority of these settings. It is certainly possible that a fixed minimum amount of $30 \mathrm{~mL} / \mathrm{kg}$ is excessive for a small fraction of patients. For instance, chronic ICU patients might not need this fixed amount of fluids and might benefit from a proper assessment of fluid responsiveness in settings where these techniques are available. But published data strongly suggest that the large majority of patients benefit from beginning resuscitation with this minimum amount. A fixed amount does not mean the physician should abandon the need to assess fluid responsiveness and titrate fluid administration accordingly. We need to frequently reevaluate the patients and limit resuscitation efforts to what is required by our individual patients. We believe it is the administration of an initial fixed minimum of $30 \mathrm{~mL} / \mathrm{kg}$ of fluids combined with frequent reassessment of fluid responsiveness that will optimize our ability to adequately resuscitate patients with severe sepsis and septic shock.

\section{Author details}

${ }^{1}$ Anesthesiology, Pain and Intensive Care Department, Federal University of Sao Paulo, Sao Paulo, Brazil. ${ }^{2}$ Latin America Sepsis Institute, Sao Paulo, Brazil. ${ }^{3}$ Department of Pulmonary and Critical Care, Alpert Medical School at Brown University, Providence, RI, USA. ${ }^{4}$ Department of Critical Care, St George's University Hospitals NHS Foundation Trust, London, UK.

\section{Compliance with ethical standards}

\section{Conflicts of interest}

The authors state that there is no conflict of interest.

Received: 1 October 2016 Accepted: 7 October 2016

Published online: 31 October 2016

\section{References}

1. Murakawa K, Kobayashi A (1988) Effects of vasopressors on renal tissue gas tensions during hemorrhagic shock in dogs. Crit Care Med 16:789-792

2. Zarbock A, Gomez H, Kellum JA (2014) Sepsis-induced acute kidney injury revisited: pathophysiology, prevention and future therapies. Curr Opin Crit Care 20:588-595
3. Maitland K, Kiguli S, Opoka RO, Engoru C, Olupot-Olupot P, Akech SO, Nyeko R, Mtove G, Reyburn H, Lang T, Brent B, Evans JA, Tibenderana JK, Crawley J, Russell EC, Levin M, Babiker AG, Gibb DM, FEAST Trial Group (2011) Mortality after fluid bolus in African children with severe infection. N Engl J Med 364:2483-2495

4. National Heart, Lung, and Blood Institute Acute Respiratory Distress (ARDS) Syndrome Clinical Trials Network, Wiedemann HP, Wheeler AP Bernard GR, Thompson BT, Hayden D, deBoisblanc B, Connors AF Jr, Hite $\mathrm{RD}$, Harabin AL (2006) Comparison of two fluid-management strategies in acute lung injury. N Engl J Med 354:2564-2575

5. Levy MM, Dellinger RP, Townsend SR, Linde-Zwirble WT, Marshall JC, Bion J, Schorr C, Artigas A, Ramsay G, Beale R, Parker MM, Gerlach H, Reinhart K, Silva E, Harvey M, Regan S, Angus DC (2010) The Surviving Sepsis Campaign: results of an international guideline-based performance improvement program targeting severe sepsis. Intensive Care Med 36:222-231

6. Levy MM, Rhodes A, Phillips GS, Townsend SR, Schorr CA, Beale R, Osborn T, Lemeshow S, Chiche JD, Artigas A, Dellinger RP (2014) Surviving Sepsis Campaign: association between performance metrics and outcomes in a 7.5-year study. Intensive Care Med 40:1623-1633

7. Rhodes A, Phillips G, Beale R, Cecconi M, Chiche JD, De Backer D, Divatia J, Du B, Evans L, Ferrer R, Girardis M, Koulenti D, Machado F, Simpson SQ, Tan CC, Wittebole X, Levy M (2015) The Surviving Sepsis Campaign bundles and outcome: results from the International Multicentre Prevalence Study on Sepsis (the IMPreSS study). Intensive Care Med 41:1620-1628

8. Noritomi DT, Ranzani OT, Monteiro MB, Ferreira EM, Santos SR, Leibel F, Machado FR (2014) Implementation of a multifaceted sepsis education program in an emerging country setting: clinical outcomes and cost-effectiveness in a long-term follow-up study. Intensive Care Med 40:182-191

9. Scheer CS, Fuchs C, Kuhn SO, Vollmer M, Rehberg S, Friesecke S, Abel P, Balau V, Bandt C, Meissner K, Hahnenkamp K, Grundling M (2016) Quality improvement initiative for severe sepsis and septic shock reduces 90-day mortality: a 7.5-year observational study. Crit Care Med (in press)

10. Rivers E, Nguyen B, Havstad S, Ressler J, Muzzin A, Knoblich B, Peterson E, Tomlanovich M (2001) Early goal-directed therapy in the treatment of severe sepsis and septic shock. N Engl J Med 345:1368-1377

11. ProCESS Investigators, Yealy DM, Kellum JA, Huang DT, Barnato AE, Weissfeld LA, Pike F, Terndrup T, Wang HE, Hou PC, LoVecchio F, Filbin MR, Shapiro NI, Angus DC (2014) A randomized trial of protocol-based care for early septic shock. N Engl J Med 370:1683-1693

12. ARISE Investigators, ANZICS Clinical Trials Group, Peake SL, Delaney A, Bailey M, Bellomo R, Cameron PA, Cooper DJ, Higgins AM, Holdgate A, Howe BD, Webb SA, Williams P (2014) Goal-directed resuscitation for patients with early septic shock. N Engl J Med 371:1496-1506

13. Mouncey PR, Osborn TM, Power GS, Harrison DA, Sadique MZ, Grieve RD, Jahan R, Harvey SE, Bell D, Bion JF, Coats TJ, Singer M, Young JD, Rowan KM, ProMISe Trial Investigators (2015) Trial of early, goal-directed resuscitation for septic shock. N Engl J Med 372:1301-1311

14. Malbrain ML, Marik PE, Witters I, Cordemans C, Kirkpatrick AW, Roberts DJ, Van Regenmortel N (2014) Fluid overload, de-resuscitation, and outcomes in critically ill or injured patients: a systematic review with suggestions for clinical practice. Anaesthesiol Intensive Ther 46:361-380

15. Liu VX, Morehouse JW, Marelich GP, Soule J, Russell T, Skeath M, Adams C, Escobar GJ, Whippy A (2016) Multicenter implementation of a treatment bundle for patients with sepsis and intermediate lactate values. Am J Respir Crit Care Med 193:1264-1270 